\title{
ÉTICA E ESTÉTICA: RECONHECENDO A CONDIÇÃO HUMANA NO ENSINO DE ENFERMAGEM
}

[Ethics and Esthetics: Recognizing the Human Condition in Nurse Education]

\author{
Sandra Ribeiro* \\ Ymiracy Nascimento de S. Polak
}

\begin{abstract}
RESUMO: Trata-se de uma reflexão teóricofilosófica, cujo objetivo é propor ao leitor-autor uma reflexão sobre a nossa condição humana e profissional. Entretanto, na condição de docentes, encontramo-nos em constante busca de significados para o vir-a-ser pessoal e profissional. A difícil tarefa do auto questionamento, para que possamos transformar a curiosidade ingênua, em curiosidade epistemológica, é instigante e ao mesmo tempo fascinante. A relação de ensino e aprendizagem em Enfermagem exige uma postura, cujo olhar estético e sensível, aproxima esses seres de uma relação ética, valorizando suas formas próprias de ser e agir profissionalmente, compreendendo a complexidade dos seres de relação que somos.
\end{abstract}

PALAVRAS-CHAVE: Enfermagem; Ensino; Ética de enfermagem; Estética.

\section{INTRODUÇÃO}

A inserção na carreira docente desperta um misto de sentimentos, abre um leque de possibilidades que sinalizam a abertura de novos conhecimentos e competências, aliada ao poder decorrente deste novo papel. Concomitante a isso, surge um sentimento não tão positivo, que é o medo de não corresponder às expectativas, tanto dos alunos, quanto às próprias. Enfim, passamos a

*Enfermeira, Professora Assistente do Centro Universitário Filadélfia de Londrina - UNIFIL, Mestranda em Enfermagem pela Universidade Federal do Paraná, membro do Grupo de Estudos Multiprofissional em Saúde do Adulto - GEMSA - do Departamento de Enfermagem da UFPR.

**Enfermeira, Doutora em Filosofia da Enfermagem pela Universidade Federal de Santa Catarina, membro do Grupo de Estudos Multiprofissional em Saúde do Adulto - GEMSA - do Departamento de Enfermagem da UFPR. conviver com uma ambivalência de sentimentos, representadas por um misto de prazer e medo.

Ressalta-se como extremamente positiva, apesar de questionada, a ingenuidade característica com que muitos docentes ingressam na carreira. Nesta etapa o jovem professor possui algo de especial, porém pouco valorizada, a experiência prática. A valorização parcial decorre de uma concepção elitista presente na academia, na qual o vivido é pouco considerado, quando não desconsiderado pelos modelos explicativos, vigentes na mesma.

Este dado reflete um certo estranhamento entre esses dois mundos, reiterando uma nova concepção que, embora não tão forte como a predominante, está silenciosamente abalando as estruturas do modelo vigente, denunciando-o com pertinência. A nova concepção é movida pela solidariedade e pela estética e nos mostra que a prática, apesar de rica, está muito distante do preconizado pela academia.

A superação do vigente revela grandes e importantes questões, muito mais profundas do que simplesmente ser professor e simplesmente "dar aula". Esta descoberta implica em aceitar o que, antes reconhecido como inexperiência, atualmente é visto como ingenuidade, que vai discretamente mostrando a complexidade, à medida que a curiosidade sobre os próprios erros mentais e a intenção de ser e fazer são desveladas. Porém, o que realmente significa esta complexidade, senão o que é tecido junto? (PENA-VEGA, ALMEIDA, PETRAGLIA, 2001). Apesar de termos a imensa necessidade de separar as partes, para depois juntá-las, como se permanecessem na mesma condição, estanque.

Inertes em nossa própria manifestação existencial, a condição humana permanece em sua 
construção histórica e cultural, mesmo que por momentos, pouco perceptível, esvaindo-se pelos dedos na temporalidade.

A difícil tarefa do auto questionamento, para quem sabe um dia conseguir transformar a curiosidade ingênua em curiosidade epistemológica, é instigante e ao mesmo tempo fascinante. Esta condição desafia a nossa escolha de ir além, de investir na formação de educadores e educandos, em respeito à condição humana, posicionando-nos diante do dever de compreender a si e ao outro, para melhor compreender o mundo em que vivemos.

Assim sendo, possivelmente abriremos espaço para uma reorganização do ensino em respeito à diversidade em que estamos inseridos, compreendendo que a questão técnica está tecida não só com a ciência, mas também, com a cultura, história, sociedade e religião. Este cenário envolve atitude ética e estética, fortalecendo o cerne das relações humanas, que passam por um período difícil, necessitando de respeito aos valores morais, envoltos na beleza conferida pela ação individualizada e cordial.

Idealizando, assim, o ensino voltado para uma formação integral e para cidadãos reais, e partindo dos pressupostos de Enfermagem ArteEstética, Ciência e Profissão-Arte, os objetivos deste artigo são: possibilitar uma reflexão ao leitor-autor sobre a nossa condição humana, considerando: os aspectos do trabalho, os complexos imaginários, o cotidiano e a relação entre os seres envolvidos, tendo em vista o vira-ser pessoal e profissional.

\section{DESENVOLVENDO O TEMA}

Para discorrermos sobre a temática abordada neste trabalho é mister, tecer considerações sobre alguns conceitos tais como: Ser Humano, Trabalho - Vida Prática, os Complexos Imaginários, Enfermagem e Cotidiano e EU-TU:

\subsection{SER HUMANO}

O ser humano é ao mesmo tempo "biofísico e psico-sócio-cultural, [...] originários do cosmos, da natureza, da vida, mas devido à própria humanidade, à nossa cultura, à nossa mente, à nossa consciência, tornamo-nos estranhos a este cosmos, que nos parece secretamente íntimo" (MORIN, 2000, p. 51).

Este ser que vive e age neste mundo, tenta mentalmente distanciar-se deste mundo, como que arrebatado em fuga, tenta manter o controle ao longe, construindo sua cultura e realizando-se por ela, em sua unidade e diversidade, utilizando-se conforme a sua vontade e necessidade de perpetuação. Traz na unidade a condição genética da espécie humana o Homo sapiens, que por ruptura do equilíbrio racional torna-se demens, e na diversidade os traços culturais, psico-afetivos, intelectuais, sociais; somos ao mesmo tempo seres semelhantes, porém com muitas diferenças, e a complexidade reside em tentar compreender esta relação entre unidade e diversidade, existentes no mesmo ser.

A complexidade está intrinsecamente marcada em todos os seres humanos, como: a racionalidade, a afetividade, o trabalho, o lúdico, o econômico, o consumista. Esta, por sua vez, reflete a inteligência empírico-racional, o indivíduo possui religiões, crenças e mitos que traduzem a sua cultura, sendo que uma característica jamais anula a outra, apenas vivem em conjunto, tecendo suas raízes antropológicas, entrelaçando a história (MORIN, 2000).

\subsection{TRABALHO - VIDA PRÁTICA}

É no trabalho que o ser humano tenta realizarse, entretanto, depara-se com uma série de obstáculos a serem enfrentados. Por ser necessária a relação de convivialidade social, pela busca da manutenção de sua produtividade e, principalmente, de sua subsistência, este meio vem tornando-se cada vez mais disputado, sendo cultuado pelas especializações, muitas vezes distantes da realidade, empobrecidas pelo conhecimento restrito, impedido de uma reflexão culturalmente contextualizada, na arrogância pelo poder econômico.

Não podemos conceber bons profissionais como meros atores técnicos, desvinculados dos problemas advindos da sociedade que os acolhe, pois desta forma de nada serviriam, predominaria um conflito, no mínimo, de cultura e comunicação. Faz-se necessário religar o social, cultural, técnico, científico, ético e estético, existentes num só ser, e aflorar a criatividade da ação própria do ser, em 
lugar do agir mecânico e frio, em série de produção materialista. A isto, a era da informação e informatização relega o ser humano, em poder subjugado de seus feitos, transferindo artificialidade e insensibilidade na relação com o outro.

Quando nos remetemos ao agir, este se refere do e pelo ser, o mesmo que se desveste da condição de semelhante, ao referir-se ao outro, portanto, é inconcebível admitir um profissional da área da saúde, tratar um semelhante com desrespeito e até mesmo desdém, mas, infelizmente é o que muito se vê por aí. Por incrível que pareça, há profissionais que firmaram juramento e agem criteriosamente em oposto ao que se comprometeram, exemplificando-se negativamente aos acadêmicos, que muitas vezes o admiram, pela firmeza de caráter transmitido, e reproduzidos por mentes de enfraquecido espírito crítico. Este agir, além de ferir a Ética Humana, reproduz a insanidade autoritária e inautêntica do Homo demens em desequilíbrio com o bom senso (MORIN, 2000; PENA-VEGA, 2001; ARENDT, 1997).

\subsection{COMPLEXOS IMAGINÁRIOS}

A vida é acompanhada de uma realidade e de um imaginário do qual fazem parte, os sonhos, as fantasias, as magias e os mitos. Estes elementos processam uma relação de troca psíquica entre o ser vivo e seu meio, alimentando a vida afetiva e interferindo na realidade da vida prática, manifestando-se por intermédio de uma tríade denominada de projeção, identificação e transferência, que acontece na vida imaginária do ser, de forma interdependente. É a projeção de desejos, medos, aspirações, necessidades, por imagens mentais que são experimentadas subjetivamente, num ir e vir do pensamento à realidade.

Podemos identificar quatro estados que caminham numa dialética entre o imaginário e a vida prática, segundo PENA-VEGA, ALMEIDA e PETRÁGLIA (2001):

- Complexos mágicos: identificam a força da religião, as crenças, os mitos, os tabus, as alienações, os amores secretos, os fetiches, reaparecendo pela subjetividade, e esta se torna objetivada na alucinação. Destinam-se ao trabalho real e também em fatos imaginários, como festividades ou preparações póstumas.
- Complexo afetivo (realista-sentimental): é associado ao sentimento realista, cuja necessidade é vital ao ser humano, também participando do imaginário em simbiose à realidade, inclui o amor, amizade, ternura, desprezo, raiva, ciúme, portanto, cada ser é distinto do outro, em consciência da realidade humana.

- Estado racional-empírico: associa coerentemente atitudes empíricas e racionais, não impedindo pela racionalidade que atitudes de fé e crenças míticas sejam desconsideradas na realidade prática, permite uma troca entre o homem prático e mítico, contemplando ao mesmo tempo, o sentimento, a razão, a magia, considerando sua unidade e diversidade.

- Estado estético-lúdico: é o do jogo da vida, no qual participam os complexos mágicos, realistasentimental, que tem consciência de se tratar de uma participação imaginária, inscrita no quadro da consciência empírico-racional.

Compreender o ser humano considerando as influências dos complexos imaginários, permite aproximar-mo-nos das possibilidades dinâmicas que interagem na vida afetiva e prática, na dialética do pensar e agir, não restringindo a uma só questão visível ou invisível seja por religião, crença ou mito que polariza este meio; e sim por significar os modelos culturais e os problemas sociais diante dos processos humanos manifestados.

\subsection{ENFERMAGEM E COTIDIANO.}

Os desafios do cotidiano na enfermagem, principalmente no âmbito da dinâmica do ensinoaprendizagem, instigam a postura de neutralidade, que além de irreal causa impressão pejorativa de descompromisso, pois no processo de formação, que não é nada neutro, abrir-se-á uma imensa gama de possibilidades, de interação simbiótica decorrentes da intencionalidade de estar com o outro numa relação de reciprocidade, entre ensinar e aprender, pautado no respeito mútuo, compartilhando os saberes e os momentos relevantes referentes à percepção de significados e exigências do agir, maneiras de construir conhecimentos, como resultado de meios de elaboração e expressão das ações de cuidado com o outro e consigo próprio.

No entanto, a compreensão do outro desvela a mente para o auto-conhecimento e auto- 
compreensão, tornando mais ameno o enfrentamento das dicotomias do cotidiano e nos faz sentir a necessidade de um novo olhar às ações. Neste sentido, concordo com Polak (1997), quando refere-se ao olhar estético, afirmando que possibilita um modo de desenvolver o processo de formação dos que trabalham na arte de cuidar, em respeito à forma de ser do outro, seus valores, conhecimentos prévios e necessidades epistemológicas, proporcionando um cenário de eticidade recíproca, que permite um vir-a-ser contemplativo e de beleza, aproximando os atores desse cotidiano, de uma interação um pouco mais feliz e de criatividade própria de cada ser que manifesta.

\subsection{EU-TU}

O homem é um ser social, e com outros se mantém em coexistência, relacionando-se num despertar de sentimentos. O Eu possui um mundo pessoal e uma forma idêntica de relacionar-se com esse mundo. No entanto, cada ser é o centro de seu mundo, podendo estar aberto para a realidade e para o outro. Cada qual relaciona-se distintamente com a sua realidade e com o outro. Posso compreender o outro a partir da experiência com o meu Eu (GONÇALVES, 1997).

Para BUBER (1974), em sua filosofia do diálogo, além de uma metafísica ou uma teologia sistemática, EU-TU é uma ontologia da relação, uma reflexão sobre a existência humana, como uma questão antropológica do sentido da existência, no qual a inter-relação ética do inter-humano ocorre pela reciprocidade, conferindo novo sentido ao mundo e às relações do homem com o mundo. $A$ palavra é uma atitude efetiva, eficaz e atualizadora do ser, pois através dela, o homem se faz e se situa no mundo com os outros, intencionalmente, dialogicamente, efetuando a fenomenologia da relação. É no encontro dialógico que se revela a totalidade do homem; e na relação dialógica estão presentes o Eu como pessoa e o TU como o outro, pois a reciprocidade atribui valor existencial ao encontro dialógico da relação inter-humana, permanecendo com parâmetro valorativo das relações EU-TU.

Quando o EU-ISSO se revela, pela postura de considerar o outro como ISSO, objeto de estudo e investigação, por exemplo, como uma norma metodológica de uma ciência, não representa o estado de ser e sim o modo de ser; ou o EU como substância, ou o TU como objeto, são considerados por Buber (1974), e décadas mais tarde por MerleauPonty apud Buber (1974), que esta condição rejeita a noção de consciência como função universal da organização da experiência, pois consideraram que esta estabelece uma rede de intenções significativas, sendo o único modo possível de unir consciência e ação.

Identifico a arte na enfermagem pela estética, como uma forma de relacionamento ético entre os semelhantes, pois no anseio de tornar-se uma obra por este meio, vivenciamos a manifestação corporal do EU-aluno, almejando a ação do poder eficaz do TU-docente, pela reciprocidade do ensino dialógico, considerando a sua unidade, não reduzindo a sua multiplicidade por fragmentação do complexo do ser-cliente, pelo diálogo, possibilitando o surgimento da obra mediante a força eficaz da experiência, da reciprocidade e da relação pelo encontro.

O encontro se dá pela presença vivenciada e pela essencialidade do momento, considerando as objetividades do passado em confluência às subjetividades do presente. O sentido da ação é enigmático, assim também como é o sentimento advindo dessa experiência, revelando a realidade pela manifestação de sentimentos no ser humano, pois esse habita em seu amor, o encontro com a liberdade e exclusividade humana, independente do tempo e espaço. Cada ser-aluno é único, e pela reciprocidade é formado e nos forma, possui a liberdade de criatividade, e esta inspira a arte.

Somos, pois, corpo que vê e sente, visto que o olhar para si, desnuda-se no confronto, diante de medos, ilusões, razões e sentimentos, exigindo a postura de assumir o risco, de termos que reconhecer a necessidade de buscar novas e melhores formas de tornar a nossa vida realmente mais plena e feliz. Na dinâmica da vida do cuidar, confrontamo-nos com a possibilidade da socialidade cotidiana, esta que perpassa a solidariedade orgânica, contrapondo-se à solidariedade mecânica; a corporeidade inspira a necessidade de estar e de ser com o outro, tocar e ser tocado, pois sem isto haveria a autodestruição dessa socialidade, que marca o movimento vivenciado e confere o sentimento estético e sensível, próprio de ser. A realidade do cuidar 
evidencia a potencialidade social do cuidador e de quem é cuidado, revelando a dialética que defronta o dever ser e o que se quer ser, incitando o ético (REZENDE et al., 1995).

A arte é uma forma de expressão, inventiva e criativa, no qual o artista utiliza como inspiração, a obra de outros e as suas próprias, a fim de criar outras novas, superando e ultrapassando outros, porque os retoma e transforma. E assim sendo, por estabelecer uma relação intrínseca com a sociedade, a estética confere finalidade pedagógica à arte, atribuindo-lhe a missão de crítica social e política, interpretação do presente e imaginação da sociedade futura, como expressão simbólica dá sentido à cultura e à história. (CHAUI, 2002).

\section{SÍNTESE REFLEXIVA}

Durante a nossa trajetória pela vida, como seres de relação com o mundo, enfrentamos diversas situações, nas quais perpassam a curiosidade ingênua à epistemológica, na evolução pela busca do conhecimento, pairando sobre a condição humana e a complexidade presente nos seres humanos no mundo, refletindo a necessidade de adotarmos uma postura de compreensão mútua.

A relação de ensino-aprendizagem em Enfermagem pede essa postura, possibilita a formação do cidadão presente na realidade, refletindo a profissão como arte e ciência, voltada ao olhar ético e estético, por um agir sensato no reconhecimento da complexidade da condição humana, como ser afetivo, religioso, racional, empírico, estético, lúdico... Identificando suas ações visíveis e invisíveis, o que forma sua história de vida em meio a uma cultura em unidade e diversidade.

Esse olhar, estético e sensível, aproxima esses seres de uma relação ética, valorizando suas formas próprias de ser e agir profissionalmente mais próximos de serem felizes.

ABSTRACT: This is a theoretical and philosophical study with the purpose of leading the reader on revealing our human and professional condition. On the process of being professors we are constantly searching the meaning of the personal and professional becoming. The uneasy task of questioning oneself to change the ingenuous curiosity into epistemological curiosity is at the same time provoking and fascinating. The nurse education and teaching relationship demands an attitude which aesthetics and sensible glance bring the human beings to an ethical relationship. This increases the value of their way of being and act professionally, understanding the complexity of being we are.

KEY WORDS: Nurse, Education, Ethics nursing, Esthetics.

\section{REFERÊNCIAS}

1. ARENDT, H. A condição humana. 8. ed. Rio de Janeiro: Forense Universitária, 1997.

2. BUBER, M. Eu e Tu. 2. ed. São Paulo: Moraes, 1974.

3. CHAUI, M. Convite à filosofia. 12. ed. São Paulo: Ática, 2002.

4. GONÇALVES, M. A. S. Sentir, pensar, agir Corporeidade e educação. 2.ed. São Paulo: Papirus, 1997.

5. MORIN, E. Os sete saberes necessários à educação do futuro. 2. ed. São Paulo: Cortez, 2000.

6. POLAK, Y. N. S. A corporeidade como resgate do humano na enfermagem. Pelotas: Universitária/UFPel, 1997.

7. PENA-VEGA, A.; ALMEIDA, C. R. S.; PETRAGLIA, I.(Org.) Edgar Morin: ética, cultura e educação. São Paulo: Cortez, 2001.

8. REZENDE, A. L. M. et al.. O fio da moiras- 0 afrontamento do destino no quotidiano da saúde. Florianópolis: Ed. da UFSC, 1995.

ENDEREÇO DASAUTORAS Rua: Belém, 309 - apto. 1401 Cabral. Curitiba - Paraná E-Mail:ynsp@hotmail.com 